\title{
Heritability of Macular Pigment: A Twin Study
}

\author{
Shiao Hui Melissa Liew, ${ }^{1}$ Clare E. Gilbert, ${ }^{2}$ Tim D. Spector, ${ }^{1}$ Jobn Mellerio, ${ }^{3}$ John Marshall, ${ }^{4}$ \\ Fredericus J. van Kuijk, ${ }^{5}$ Stephen Beatty, ${ }^{6}$ Fred Fitzke, $^{7}$ and Christopher J. Hammond ${ }^{1,8}$
}

Purpose. Several studies have reported higher levels of macular pigment (MP) in association with reduced risk for age-related macular degeneration (ARMD), a disease to which there is a genetic predisposition. A classic twin study was performed to determine the heritability of MP in the healthy eye.

Methods. One hundred fifty twin pairs (76 monozygotic [MZ] and 74 dizygotic [DZ]), aged 18 to 50 years, participated. MP optical density was measured psychophysically with heterochromatic flicker photometry (HFP) and also with an imaging method involving fundus autofluorescence (AF). The covariance of MP within MZ and DZ twin pairs was compared, and genetic modeling techniques were used to determine the relative contributions of genes and environment to the variation in MP.

RESults. The mean MP optical density, measured using HFP, was $0.43 \pm 0.21$. Using $\mathrm{AF}$, the mean $\mathrm{MP}$ optical density, measured at $1^{\circ}$ eccentricity, was $0.28 \pm 0.11$. MP optical densities correlated more highly in $\mathrm{MZ}$ twins than in $\mathrm{DZ}$ twins, according to both HFP (MZ: 0.65; DZ: 0.24) and AF (MZ: 0.83; DZ: 0.50). A model combining additive genetic and unique environmental effects provided the best fit and resulted in MP heritability estimates of 0.67 (95\% CI, 0.52-0.77) and 0.85 (95\% CI, 0.78-0.90) for HFP and AF readings, respectively.

Conclusions. This classic twin study demonstrates that genetic background is an important determinant of MP optical density, reflected in heritability estimates of 0.67 and 0.85 for HFP and $\mathrm{AF}$ measures, respectively. (Invest Ophthalmol Vis Sci. 2005; 46:4430 - 4436) DOI:10.1167/iovs.05-0519

$\mathrm{L}_{\mathrm{i}}^{\mathrm{s}}$ utein $(\mathrm{L})$ and zeaxanthin $(\mathrm{Z})$ are the only carotenoids found in the human macula, where they accumulate to the exclusion of all other carotenoids, and where they are collectively

From the ${ }^{1}$ Twin Research and Genetic Epidemiology Unit and the ${ }^{4}$ Department of Ophthalmology, The Rayne Institute, St. Thomas' Hospital, London, United Kingdom; the ${ }^{2}$ International Centre for Eye Health, London School of Hygiene and Tropical Medicine, University of London, London, United Kingdom; the ${ }^{3}$ School of Biosciences, University of Westminster, London, United Kingdom; the ${ }^{5}$ Department of Ophthalmology and Visual Sciences, University of Texas Medical Branch, Galveston, Texas; the ${ }^{6}$ Department of Chemical and Life Sciences, Waterford Institute of Technology, Waterford, Ireland; the ${ }^{7}$ Institute of Ophthalmology, London, United Kingdom; and the ${ }^{8}$ Princess Royal University Hospital, Bromley Hospitals NHS Trust, Orpington, United Kindgom.

Supported by the Wellcome Trust. The St. Thomas' United Kingdom Adult Twin Registry receives support from the Arthritis Research Campaign, British Heart Foundation, and the Chronic Disease Research Foundation.

Submitted for publication April 27, 2005; revised July 28, 2005; accepted October 17, 2005.

Disclosure: S.H.M. Liew, None; C.E. Gilbert, None; T.D. Spector, None; J. Mellerio, None; J. Marshall, None; F.J.G.M. van Kuijk, None; S. Beatty, None; F. Fitzke, None; C.J. Hammond, None

The publication costs of this article were defrayed in part by page charge payment. This article must therefore be marked "advertisement" in accordance with 18 U.S.C. $\$ 1734$ solely to indicate this fact.

Corresponding author: Christopher J. Hammond, Twin Research and Genetic Epidemiology Unit, St. Thomas' Hospital, Lambeth Palace Road, London SE1 7EH, UK; chammond@btopenworld.com. known as macular pigment (MP). ${ }^{1} \mathrm{~L}$ and $\mathrm{Z}$ are two hydroxycarotenoids and are entirely of dietary origin. ${ }^{2}$ The optical density of MP peaks at the center of the fovea and, within the layer structure of the retina, is maximally concentrated in the inner and outer plexiform layers. ${ }^{3,4}$

It is believed that MP may protect the retina from photooxidative damage, ${ }^{5,6}$ which is primarily caused by blue light, because of its prereceptorial location and absorbance spectrum (which peaks at $460 \mathrm{~nm}$ ). ${ }^{7,8} \mathrm{~L}$ and $\mathrm{Z}$ may also contribute to the antioxidant defense of the retina by actively quenching reactive oxygen intermediates (ROIs), as direct oxidation products of these carotenoids have been found in the human retina.?

Although the pathogenesis of age-related macular degeneration (ARMD), which is the leading cause of blindness in the developed world, ${ }^{10}$ remains unclear, there is a growing body of evidence in support of the view that oxidative stress plays an important role. ${ }^{11,12}$ The anatomic, antioxidant, and absorptive properties of MP have, unsurprisingly, stimulated interest in the possibility that MP may protect against ARMD. Indeed, the dietary origins of MP render this hypothesis all the more provocative. However, the evidence to date is limited to crosssectional studies and is inconsistent. In brief, parallels have been drawn between risk for ARMD and a relative lack of MP (and/or serum concentrations of its constituent carotenoids) in some but not all studies. ${ }^{13-18}$

MP levels vary greatly between individuals, ${ }^{8,19}$ and are influenced by many factors, including diet, percentage body fat, and tobacco use..$^{20-25}$ Although MP is entirely of dietary origin, primarily from fruits and vegetables such as maize, peppers, and spinach, ${ }^{26}$ idiosyncratic differences in the absorption, transport, retinal capture, and stabilization of $\mathrm{L}$ and $\mathrm{Z}$ are also likely to play a role in the determination of this pigment's concentration within the macula. Indeed, and given the genetic predisposition to ARMD, ${ }^{27-30}$ the role of genes in the determination of MP levels warrants investigation. We report the results of a classic twin study designed to investigate the relative contributions of genetic and environmental factors to macular pigment levels in the healthy eye.

\section{Methods}

\section{Subjects}

One hundred fifty pairs of healthy, female twins (76 monozygotic [MZ], 74 dizygotic [DZ]), aged 18 to 50 years, were recruited from the TwinsUK adult registry held at St. Thomas' Hospital, London. All subjects were volunteers recruited from the general population through local and national media campaigns and were unaware of proposals for future eye studies, hopefully minimizing ascertainment bias. Those who met the age criteria (16-50 years) were later invited to participate. The upper age limit was set at 50 years, to increase the likelihood of recruiting subjects with healthy retinas and clear lenses. Informed consent was obtained from each volunteer, and with local ethics committee approval, the research procedures adhered to the tenets of the Declaration of Helsinki.

An ocular history and examination were performed on all subjects, including a dilated fundus assessment. Subjects with any retinal disease on standardized dilated funduscopy (including any drusen) or previous 
ocular surgery were excluded. One twin pair was excluded from the study due to the presence of drusen in one of the pair.

Zygosity was determined by a standardized questionnaire, which has been shown to be at least $95 \%$ accurate. ${ }^{31}$ In cases in which there was any doubt concerning zygosity, DNA analysis of short tandemrepeat polymorphisms was performed (AmpF1 STR Profiler kit; Applied Biosystems, Foster City, CA). DNA analysis was performed in 68 (45\%) of the twin pairs.

\section{Macular Pigment Measurement}

MP was measured by a single investigator who used two different techniques: a subjective psychophysical method and an objective method.

\section{Heterochromatic Flicker Photometry}

Basic Principles. Heterochromatic flicker photometry (HFP) is a psychophysical test that uses the absorption characteristics of MP, and the fact that it is optically undetectable at $6^{\circ}$ to $8^{\circ}$ eccentricity from the foveal center, to calculate the optical density of this pigment. ${ }^{7,32}$ The test field flickers between a light that has a wavelength close to the peak absorption of MP (blue light, $\lambda_{\max }=468 \mathrm{~nm}$ ) and a longer reference light, which has a wavelength close to minimum or zero absorption by MP (green light, $\lambda_{\max }=535 \mathrm{~nm}$ ). It is assumed that the presence of MP decreases the spectral sensitivity of macular photoreceptors to blue light. During this test, the green reference light remains at a fixed luminance, and the subject using a dial can vary the blue light intensity. The amount of blue light luminance necessary to achieve matching luminance with the green light is a measure of MP optical density. When the luminances of the blue and green light are closely matched, the subject perceives minimum flicker. A minimum flicker match is made in the following two locations: when the retinal image of the target field lies on the fovea and when the retinal image of the target field lies in the parafovea, where there is minimal or no MP. The logarithm of the ratio of the blue luminosity for the foveal match to the blue luminosity of the parafoveal reference match, gives a measure of the MP optical density. A blue background $\left(\lambda_{\max }=428\right.$ $\mathrm{nm}$ ) is used to exclude the participation of the S-cones, and the flicker rate is chosen to be above the critical fusion frequency to exclude rod involvement.

Apparatus and Procedure. The apparatus we used in this study, the Maculometer (Mellerio J, School of Biosciences, University of Westminster, London, UK), uses light-emitting diodes that emit near-monochromatic light. ${ }^{33}$ The subject views the foveal target at a distance of $330 \mathrm{~mm}$, which subtends a diameter of $1^{\circ}$ at the eye. For the parafoveal reference match, where it is assumed there is no MP, the test field is an annulus of $10^{\circ}$ (inner diameter) with a width of $1^{\circ}$. The Maculometer uses central fixation for the parafoveal match, when the foveal test field is switched to a dim red spot to provide a fixation target. Thus, the subject is always fixating on the central $1^{\circ}$ field.

The Maculometer is a compact, portable instrument and was placed on a tabletop at an angle of $35^{\circ}$. Subjects were tested in normal office lighting. The target fields were viewed through an aperture, and subjects were asked to rest their foreheads against a guide that placed them $330 \mathrm{~mm}$ away from the target. The test was explained to each subject, and he or she was allowed to make two trial minimum flicker matches before measurements were recorded. After each match was made, the examiner moved the dial to a random position. Five foveal readings were obtained first, followed by five parafoveal readings. HFP was performed in both eyes, with the first eye to be tested alternating in each subsequent twin pair tested.

HFP Test-Retest Variability. One eye per subject was chosen randomly in 17 healthy volunteers. Each subject was tested on two occasions, separated in time by at least 1 day (but no more than 30 days), by the principal investigator (SHML). The differences in MP optical densities obtained on these two separate visits were then calculated for each subject. The mean intersession difference was

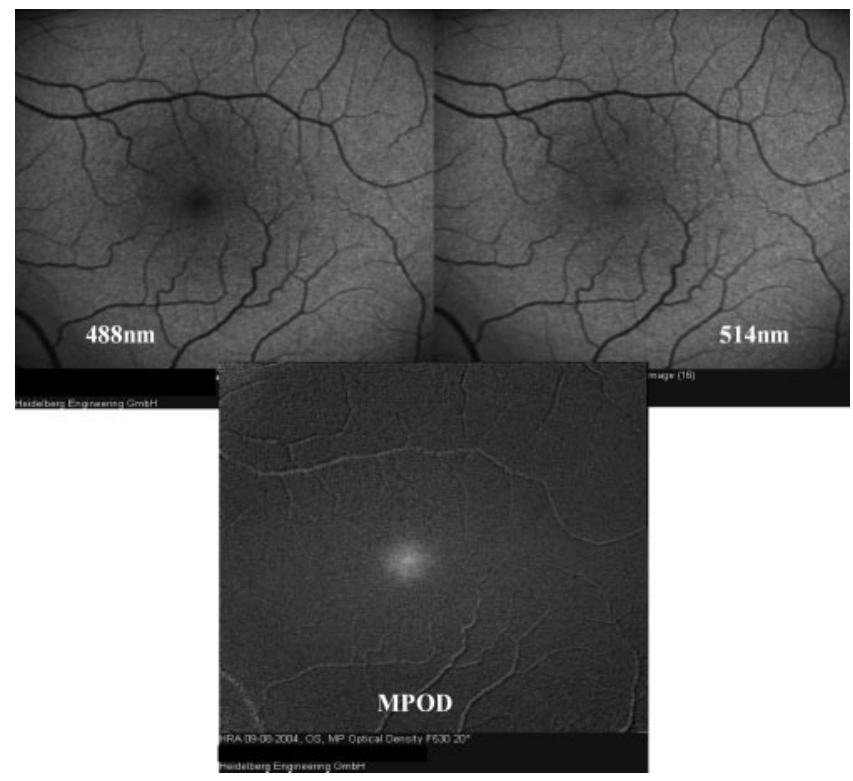

FigURE 1. Autofluorescence images taken at 488 and $514 \mathrm{~nm}$ (top). MPOD (bottom) is the generated MP optical density map.

$0.10 \pm 0.11$ (SD; range, $0.02-0.39)$. The mean coefficient of variation for MP readings was $17.6 \% \pm 16.5 \%(\mathrm{SD})$.

\section{Fundus Autofluorescence}

Basic Principles. This technique takes advantage of the autofluorescence (AF) characteristic of lipofuscin that is found in the retinal pigment epithelium (RPE), and is described in detail elsewhere. ${ }^{34}$ Lipofuscin AF can be excited in vivo by wavelengths of light between 400 and $570 \mathrm{~nm}$, and $\mathrm{AF}$ is emitted in the range of 520 to 800 $\mathrm{nm} .^{35,36}$ As the MP absorption range $(400-550 \mathrm{~nm})$ is within the excitation range of lipofuscin, ${ }^{3}$ its presence will cause attenuation of the AF due to absorption of light by MP before it reaches the lipofuscin. The principle of this technique is that the amount of light absorption by the MP is strongly related to the amount of MP within the retina and can therefore provide a measure of MP optical density. ${ }^{37}$

Two different wavelengths of light are used to stimulate AF, one that is well absorbed by MP and one that is minimally absorbed by MP. Using a wavelength that is minimally absorbed by MP provides reference values for AF emitted in the absence of MP, as this is not uniform across the field. ${ }^{38}$ A barrier filter is then used to ensure that AF readings are taken above or near the threshold of MP absorption, to ensure a single-pass measurement of MP optical density. In this way, a comparison of AF intensity recorded at the two different wavelengths allows quantification of MP optical density.

Apparatus and Procedure. A modified confocal scanning laser ophthalmoscope (Heidelberg Engineering, Heidelberg, Germany) was used to obtain high resolution, $20^{\circ}$ field AF images (Fig. 1) at 488 $\mathrm{nm}$ (blue) and $514 \mathrm{~nm}$ (green). The two wavelengths were provided by an argon laser and a band-pass filter, with a cut off at $530 \mathrm{~nm}$, to ensure a single-pass measurement of MP optical density. A program has been developed that creates a MP optical density map, generated with a gray-scale index of intensity and by digital subtraction of the AF images taken at the two different wavelengths. ${ }^{39}$ Figure 1 shows a computed MP optical density image, with areas of higher optical densities shown as brighter areas than those with lower MP densities. The program creates an MP optical density curve based on the MP image generated and centered on the foveal center (Fig 2). A vertical line marks the plateau of optical density. The plateau indicates maximum $\mathrm{AF}$ and defines the offset for no MP. Correction factors take into account the small amount of MP absorption at the 514-nm wavelength. In this study, we evaluated the MP optical density at $1^{\circ}$ eccentricity from the foveal center. 


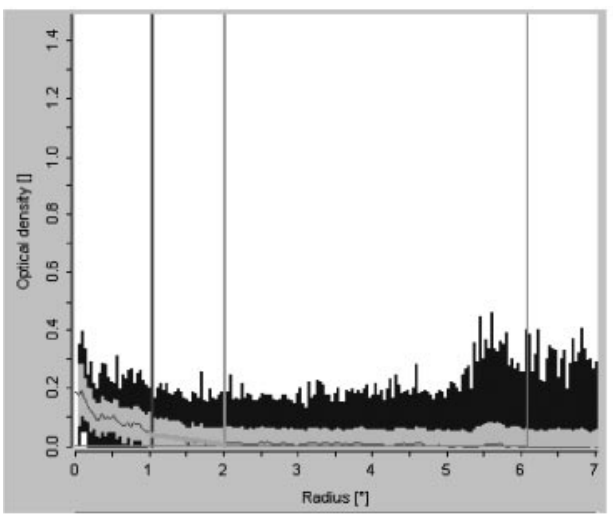

DZ Twin 1

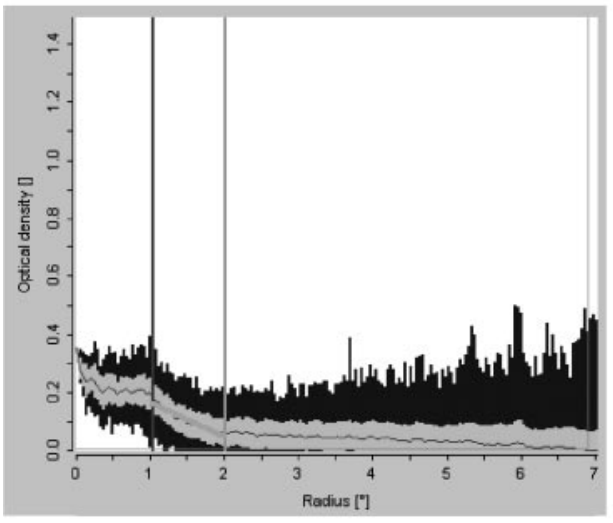

MZ Twin 1

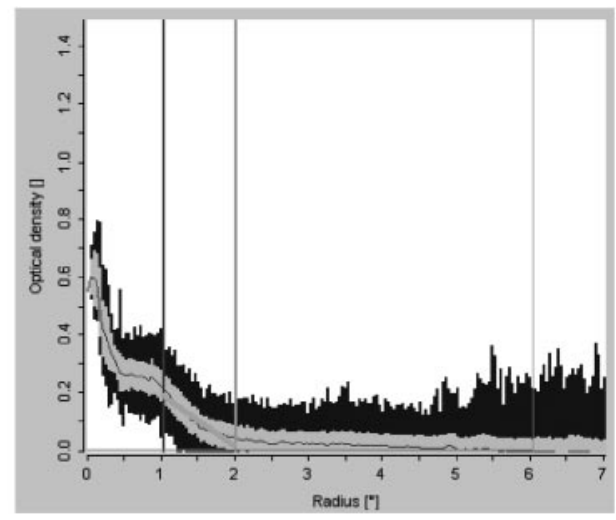

DZ Twin 2

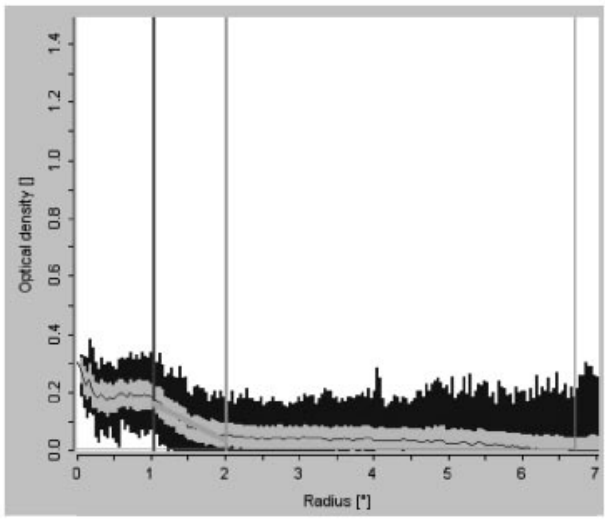

MZ Twin 2
Figure 2. MP optical density profiles of a pair each of $\mathrm{DZ}$ and $\mathrm{MZ}$ twins.
After completing the HFP test, all subjects had their pupils dilated with $1 \%$ tropicamide. Twenty to 30 minutes later, the AF test was performed in a darkened room, first in the right eye and then in the left. The luminance of the laser was fixed and remained constant for all subjects throughout the study.

AF Test-Retest Variability. Eight healthy volunteers were tested on two separate occasions within 1 month. One eye of each subject was chosen at random to undergo the AF procedure, which was performed by a single investigator. The MP density at $1^{\circ}$ from the foveal center was evaluated, and the difference obtained on the two separate visits was calculated for each subject. The mean intersession difference was $0.02 \pm 0.02$ (SD) with a range of 0 to 0.05 . The mean coefficient of variation for MP readings was 3.3\% $\pm 2.1 \%$ (SD).

\section{Data Analysis}

Data analysis and statistical tests were performed on computer (Stata, ver. 8 SE; Stata Corp., College Station, TX). Maximum-likelihood modeling with the Mx program ${ }^{40}$ was performed to estimate the heritability of MP optical density. ${ }^{41}$ This method is based on comparing the covariances of a measured trait between MZ and DZ twins. The observed phenotypic variance can be divided into additive genetic (A), dominant genetic (D), common environmental (C), and unique environmental (E) components. The common environmental component estimates the contribution of family environment, which both twins are assumed to share ${ }^{42}$ whereas the unique environmental component estimates the effects that apply only to each individual, including measurement error. Any greater similarity between MZ twins and DZ twins is attributed to greater sharing of genetic influences. Heritability is defined as the proportion of the phenotypic variation attributable to genetic factors, and is given by the equation, $\boldsymbol{b}^{2}=(\mathrm{A}+\mathrm{D}) /(\mathrm{A}+\mathrm{D}+$ $\mathrm{C}+\mathrm{E}$ ). The Akaike information criterion (AIC) was used to determine the best-fitting model, with the lowest AIC suggesting the best fit. Unless otherwise stated, the results are expressed as the mean \pm SD.

\section{Results}

One hundred fifty female twin pairs were examined (76 MZ, 74 $\mathrm{DZ}$ ) in this study. Of these, 144 twin pairs were white (MZ: 73; DZ 71), 2 pairs were of mixed race (DZ: 2), and 4 pairs were Afro-Caribbean (MZ: 3; DZ: 1). The mean age of all subjects was $39.5 \pm 8.1$ (range, 18-50) years, with no significant difference in age between MZ (mean, $38.6 \pm 8.5$ years; range, $18-50$ ) and DZ twin pairs (mean, $40.5 \pm 7.6$ years; range, $23-50$ ). Twentythree twin pairs were in the 18- to 30-year age range (MZ: 15; DZ 8), 61 pairs were in the 31- to 40-year range (MZ: 32; DZ: 29), and 66 pairs were in the 41- to 50-year range (MZ: 29; DZ: 37).

The HFP measurements in the right and left eye in each individual correlated significantly, with an intraclass correlation of $0.77(P<0.001)$; mean MP optical density was $0.43 \pm$ 0.20 and was equal in the right and left eyes (right eyes: mean, $0.43 \pm 0.22$; range, -0.21 to +1.25 ; left eyes: mean $0.43 \pm$ 0.20 ; range, -0.16 to +1.09 ). Therefore, further analysis was performed using the mean MP optical density of both eyes of each subject. Overall, MP optical densities demonstrated a normal distribution, which was confirmed by performing a skew test for normality ( $P=0.13$; Fig. 3$)$. There was no significant difference $(P=0.12$, unpaired $t$-test $)$ in MP optical density between MZ twins (mean, $0.41 \pm 0.20$ ) and DZ twins (mean, $0.45 \pm 0.20$ ), with similar distributions (Table 1). Of the 150 twin pairs examined, two subjects were unable to perform the HFP test reliably.

The AF measurements of the MP optical density in each subject's right and left eyes also correlated highly, with an intraclass correlation $(r)$ of 0.96 . Mean MP optical density, at $1^{\circ}$ from the foveal center, was the same for the right and left eyes of 0.28 (right eye: SD 0.11; range, 0.05-0.69; left eye: SD 0.11; 


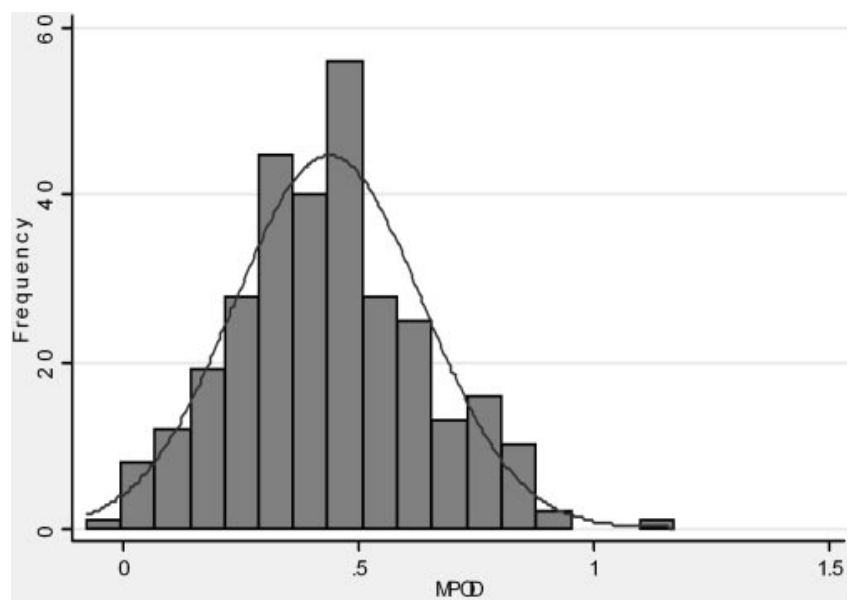

Figure 3. Frequency distribution of MP optical density values obtained with the Maculometer.

range, 0.01-0.73). We therefore used the mean optical density in both eyes of each individual. MP optical densities using the AF method showed a reasonable distribution (Fig. 4), although they were not normally distributed statistically (skew test, $P=$ 0.013). Group MP optical density using the AF method was also statistically similar for MZ and DZ twin pairs (difference of means $=0.02, P=0.08$, unpaired $t$-test), shown in Table 1 .

To investigate the relationship between MP and age, we randomly selected one subject from each twin pair to avoid bias due to their family relationship. Using HFP, we did not find any correlation between MP optical density and age $(P=0.19)$. Using AF, we found a very small increase in MP density with age $\left(r^{2}=0.03 ; P=0.03\right)$.

Using HFP, the correlation of MP optical density within MZ twin pairs was significantly higher than within DZ pairs, represented by product moment correlations of 0.65 and 0.24 , respectively. When we analyzed the right and left eyes separately, the correlations within $\mathrm{MZ}$ and $\mathrm{DZ}$ pairs were very similar in the left eyes ( 0.64 and 0.20 , respectively), but an attenuation of MZ twin correlation was observed in the right eyes (0.52). The DZ correlation remained virtually unchanged (0.19). The reasons for this are unclear.

AF revealed a similar pattern, with an $\mathrm{MZ}$ correlation of 0.83 compared with a DZ correlation of 0.50 . When right and left eyes were analyzed separately, the correlations were very similar for both eyes (right eyes: 0.81 and 0.46 ; left eyes: 0.82 and 0.51 ). Figure 2 shows the spatial distribution curves for a pair of MZ twins, illustrating the close correlation in peak MP density and distribution profile for the MZ pair compared with the DZ pair.

Maximum-likelihood modeling revealed the best fitting model for MP optical density to be the one that combined both

TABLe 1. Summary of Macular Pigment Optical Density Results Obtained with Heterochromatic Flicker Photometry and Autofluorescence Methods

\begin{tabular}{lcc}
\hline & MZ & DZ \\
\hline Mean age (y) & $38.6(8.45)$ & $40.5(7.55)$ \\
Mean HFP MPOD & $0.41(0.20)$ & $0.45(0.20)$ \\
$\quad n$ & 74 & 74 \\
Mean AF MPOD & $0.26(0.09)$ & $0.28(0.11)$ \\
$\quad n$ & 76 & 74 \\
Intraclass correlation of HFP MPOD & 0.68 & 0.21 \\
Intraclass correlation of AF MPOD & 0.83 & 0.49 \\
\hline
\end{tabular}

SD is in parentheses. MPOD, macular pigment optical density.

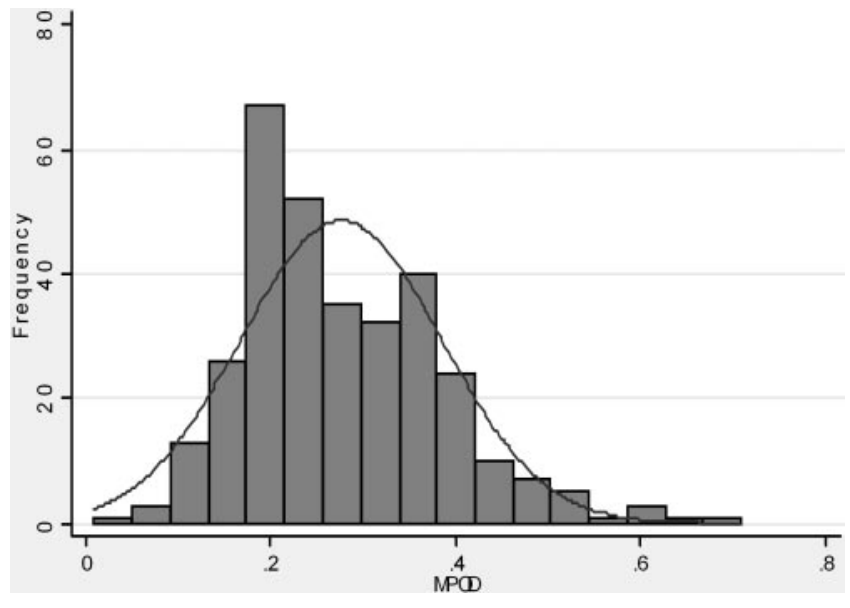

FIGURE 4. Frequency distribution of MP optical density obtained with the autofluorescence method.

additive genetic effects and unique environmental effects (AE model), for both the HFP and AF measurements (Table 2). The effects of common environment and dominant genetic effects can be removed from the model without significant loss of fit, thus suggesting that these factors are less important. According to HFP results, the heritability of MP optical density was estimated to be 0.67 (95\% CI, 0.52-0.77), with the remaining variance attributable to unique environmental effects 0.33 (95\% CI, 0.23-0.48). When AF measurements were used, the heritability estimate was higher, 0.85 (95\% CI, 0.78-0.90), with the remaining variance again attributable to unique environmental effects 0.15 (95\% CI, $0.10-0.22)$.

\section{Discussion}

In this classic twin study, we obtained MP measurements in 76 $\mathrm{MZ}$ and $74 \mathrm{DZ}$ twin pairs, enabling us to comment on the heritability of this dietary pigment at the macula.

In our study, the mean MP optical density of the entire study group was $0.43 \pm 0.20$ using HFP, comparable to other studies using the same Maculometer in healthy eyes $(0.36 \pm 0.15$ in 64 normal, female eyes). ${ }^{33}$ Beatty et al. ${ }^{43}$ and Werner et al. ${ }^{44}$ also recorded similar values in healthy subjects, where HFP with a similar stimulus size $\left(0.95 / 1^{\circ}\right.$ respectively) was used, with mean MP optical densities of 0.496 and 0.39 , respectively.

TABLE 2. Results of Maximum-Likelihood Modeling of Macular Pigment Optical Density, Obtained with HFP and AF

\begin{tabular}{lrrlc}
\hline Model & \multicolumn{1}{c}{$\boldsymbol{\chi}^{2}$} & DF & $\boldsymbol{P}$ & AIC \\
\hline HFP MPOD & & & & \\
ACE & 4.294 & 3 & 0.231 & -1.706 \\
ADE & 2.664 & 3 & 0.446 & -3.336 \\
AE & 4.294 & 4 & 0.368 & -3.706 \\
CE & 19.314 & 4 & 0.001 & 11.314 \\
E & 49.924 & 5 & 0 & 39.924 \\
AF MPOD & 2.276 & 3 & 0.517 & -3.724 \\
ACE & 2.504 & 3 & 0.475 & -3.496 \\
ADE & 2.504 & 4 & 0.644 & -5.496 \\
AE & 31.466 & 4 & 0 & 223.466 \\
CE & 110.680 & 5 & 0 & 100.68 \\
E & & & & \\
\hline
\end{tabular}

A, additive genetic; D, dominant genetic; C, common environment; E, unique environment; $\chi^{2}$, goodness of fit statistic; DF change in degrees of freedom between submodel and full model; $P$, probability that change in $\chi^{2}$ is zero; AIC, Aikake information criterion. 
Other studies have reported lower mean values, possibly attributable to differences in the HFP instrumentation and the population studied. ${ }^{45,46}$

MP readings using AF (MP optical density measured at $1^{\circ}$ eccentricity from the foveal center, $0.27 \pm 0.10$ ) are comparable with those of Wustemeyer et al. ${ }^{39}$ (average MP optical density in the $2^{\circ}$ diameter area, $0.22 \pm 0.07$ ), who used a very similar apparatus and MP density calculation program. Delori et al. ${ }^{34}$ reported a higher mean MP optical density, averaged in a $2^{\circ}$ diameter, of $0.37 \pm 0.12$, but $\mathrm{AF}$ images in that study were acquired with a modified fundus camera with different excitation wavelengths, possibly contributing to the higher readings.

There is a general consensus that MP measurements recorded with HFP, using a circular and central target, represents the optical density of this pigment at a retinal location 0.5 to 0.7 of the foveal test field diameter. Therefore, with a $1^{\circ}$ foveal target, as was used in the present study, HFP readings reflect MP densities from retinal loci of approximately $0.3^{\circ}$ eccentricity from the foveal center. ${ }^{19,47}$ Because MP densities derived from $\mathrm{AF}$ reflect readings obtained at $1^{\circ}$ eccentricity, and because MP optical density peaks at the fovea, it is not surprising that we found our AF readings to be lower than HFP readings.

It is important to note that the strength inherent in a classic twin study rests on the ability to compare a variable in $\mathrm{MZ}$ and DZ twin pairs and thus determine the relative contributions of genes and environment with respect to the variable in question. In other words, as long as a single and reproducible technique is used for all subjects, the relative nature of the readings will determine the conclusion. Therefore, despite the difficulties inherent in all methods of measuring MP in vivo, the heritability of MP levels can be studied in a meaningful way as a result of our findings.

Subjects' MP optical densities covered a wide range, according to both HFP and AF, which is consistent with most studies that have reported considerable interindividual variability. $8,19,48,49$

Both the AF and HFP results show that genetic factors and environmental risk factors not shared by twins are influential in MP optical density in this population. This classic twin study has enabled us to quantify the relative contributions of genetic and environmental effects in determining variability of MP optical density, with heritabilities of 0.85 and 0.67 for $\mathrm{AF}$ and HFP, respectively. Unique, individual environmental effects, which could include lifestyle and dietary factors, accounted for the remaining variance of MP levels. Our finding is in agreement with a study by Bone et al. ${ }^{50}$ who measured MP optical density using HFP in 19 subjects and also assessed dietary intake and serum levels of $\mathrm{L}$ and $\mathrm{Z}$, and estimated that $17 \%$ of the variability of MP optical density was attributable to dietary intake of $\mathrm{L}$ and $\mathrm{Z}$. To our knowledge, there has been only one previous twin study of MP in which 10 pairs of MZ (but not DZ) twins were studied, thereby precluding comment on the heritability of MP. ${ }^{51}$ In that study, significant differences in MP were found in five pairs of twins, moderately related to dietary differences, and thus confirming that MP was not entirely genetically determined.

As measurement error is included in the unique environmental variance, the higher heritability estimated by $\mathrm{AF}(0.85)$ compared with HFP (0.67) may be attributable to the greater measurement error and imprecision of HFP, as it is a psychophysical method. Further evidence of this is the lower interocular correlation of HFP readings $(0.77)$ compared to AF measurements $(0.96)$.

Genetic factors may play a role in every step of MP accumulation, from digestion and absorption of carotenoids in the diet, to the transport of these substances in the bloodstream and their capture by and stabilization within the retina. Many of the mechanisms involved in delivery of $\mathrm{L}$ and $\mathrm{Z}$ to tissues remain unstudied, including the precise way by which carotenoids are taken up by intestinal mucosal cells. Carotenoids are transported as chylomicrons from the gastrointestinal system to the lymphatic or portal circulation and lipoproteins transport $\mathrm{L}$ and $\mathrm{Z}$ from the liver to the retina. ${ }^{52,53}$ Genetic factors have been shown to play an important role in determining plasma lipoprotein profile. ${ }^{54,55}$ The high concentration of $\mathrm{L}$ and $\mathrm{Z}$ in the retina, to the exclusion of all other carotenoids found abundantly in the human plasma, suggests that there are specific mechanisms involved in the uptake and/or stabilization of MP. Highly specific membrane-associated xanthophyllbinding proteins (XBP), which are saturable, have now been identified in the retina. ${ }^{56,57}$ However, the exact physiological roles of these XBPs have yet to be elucidated.

The results of this study suggest a greater role for genes than may have been expected, partly because environmental factors such as nutrition and cigarette smoking have been investigated more extensively than have genetic factors. There is growing interest in the effects of dietary modification and supplementation on MP optical density, primarily because of the protection that this pigment may confer against ARMD. Although most cross-sectional studies show some relationship between dietary intake of L (and Z) and MP optical density, there is considerable interindividual variability of MP optical density and its response to dietary intervention. For example, Hammond et al. ${ }^{22}$ showed that MP levels did not increase in a substantial proportion of subjects $(3 / 11 ; 27 \%)$ after dietary modification designed to augment intake of $\mathrm{L}$ and $\mathrm{Z}$. Our results suggest that these differences, which may be due in part to other dietary factors (such as fat and iron), ${ }^{48}$ may also be due to genetic differences between individuals. The recent evidence that a common variant in the complement factor $\mathrm{H}$ $(\mathrm{CFH})$ gene is strongly associated with ARMD highlights the complex integration of genetic and environmental factors. ${ }^{28,58}$ Clearly, further work is needed, to determine whether there is any relationship between $C F H$ allelic status and MP optical density. In this study, the AF method allowed us to generate MP spatial profiles and we identified different shaped profiles, consistent with the findings of previous investigators. ${ }^{37}$ We also noted that MP spatial profiles among MZ twins tended to correlate better than those of DZ twins, suggesting that genes may influence the spatial distribution as well as quantity of MP in the eye (Fig 2).

All the twins examined in this study were female because of the difficulty in recruiting enough male subjects to make any significant comment on gender differences. The TwinsUK adult registry database has a much higher proportion of women, partly because it was set up to study osteoporosis in women. Although several large studies have not shown any difference in MP optical density between males and females, ${ }^{25,34,45,59}$ a few have found males to have significantly higher levels. ${ }^{33,46,48}$ Because our MP readings were comparable to those in other studies and twins have been shown to be comparable to singletons in many complex traits, ${ }^{60}$ we believe the results are generalizable but should be interpreted with caution in relation to men.

Ninety-six percent of our subjects were white and from the United Kingdom. At present, there are no substantial data that examine racial differences in MP optical density. Bone and Sparrock $^{49}$ performed a small study on 49 subjects to investigate differences between racial groups but found no systematic difference in peak MP density. ${ }^{49}$ As there is no gold standard for the measurement of MP density, it is difficult to compare values obtained from studies of different populations due to differences in the instrumentation, methodology, and levels of analysis performed.

This study, examining 18- to 50-year-old subjects, did not reveal any significant association between age and MP, using 
HFP results. Although the AF values suggested a positive correlation between MP optical density and age, the intraclass correlation coefficient was very small $\left(r^{2}=0.03\right)$, and the spread of data points was large. Although we attempted to recruit subjects evenly distributed by age through the age range (16 to 50 years), there were more subjects at the older end of the spectrum ( $44 \%$ aged $41-50$ years). So far, the results of previous studies investigating this relationship have also been inconsistent. Several studies agree with our HFP findings of no age-related change. ${ }^{32,33,44}$ Some studies have shown an age-related decline ${ }^{18,46}$ or increase in MP density, ${ }^{34}$ but the data have generally had a large spread and the regression coefficients have been small $\left(r=-0.14,{ }^{46}-0.05 \log\right.$ units per decade calculated from the best-fit line ${ }^{18}$ ). Large, prospective long-term studies have not yet been performed but given that age is the most important risk factor for ARMD, the relationship between MP levels and age warrants investigation in a longitudinal fashion.

In conclusion, this study reveals that genetic factors play an important role in determining the MP optical density in the healthy eye, with heritability estimates of 0.67 and 0.85 using HFP and AF methods of MP quantification. Given the genetic predisposition to ARMD and the protection MP may afford against development of that condition, the mechanisms whereby genes influence MP optical density and distribution warrants investigation.

\section{Acknowledgments}

The authors thank all the twin pairs who volunteered to participate in the study.

\section{References}

1. Bone RA, Landrum JT, Tarsis SL. Preliminary identification of the human macular pigment. Vision Res. 1985;25:1531-1535.

2. Malinow MR, Feeney-Burns L, Peterson LH, Klein ML, Neuringer M. Diet-related macular anomalies in monkeys. Invest Ophthalmol Vis Sci. 1980;19:857-863.

3. Snodderly DM, Brown PK, Delori FC, Auran JD. The macular pigment. I. Absorbance spectra, localization, and discrimination from other yellow pigments in primate retinas. Invest Opbthalmol Vis Sci. 1984;25:660-673.

4. Handelman GJ, Dratz EA, Reay CC, van Kuijk JG. Carotenoids in the human macula and whole retina. Invest Opbthalmol Vis Sci. 1988;29:850-855.

5. Schalch W, Weber P. Vitamins and carotenoids-a promising approach to reducing the risk of coronary heart disease, cancer and eye diseases. Adv Exp Med Biol. 1994;366:335-3350.

6. Krinsky NI, Landrum JT, Bone RA. Biologic mechanisms of the protective role of lutein and zeaxanthin in the eye. Annu Rev Nutr. 2003;23:171-201.

7. Snodderly DM, Auran JD, Delori FC. The macular pigment. II. Spatial distribution in primate retinas. Invest Opbthalmol Vis Sci. 1984;25:674-685.

8. Pease PL, Adams AJ, Nuccio E. Optical density of human macular pigment. Vision Res. 1987;27:705-10.

9. Khachik F, Bernstein PS, Garland DL. Identification of lutein and zeaxanthin oxidation products in human and monkey retinas. Invest Ophthalmol Vis Sci. 1997;38:1802-1811.

10. Klein R, Klein BE, Linton KL. Prevalence of age-related maculopathy. The Beaver Dam Eye Study. Opbthalmology. 1992;99:933943.

11. Beatty S, Koh H, Phil M, Henson D, Boulton M. The role of oxidative stress in the pathogenesis of age-related macular degeneration. Surv Ophthalmol. 2000;45:115-134.

12. Margrain TH, Boulton $M$, Marshall J, Sliney DH. Do blue light filters confer protection against age-related macular degeneration? Prog Retin Eye Res. 2004;23:523-531.

13. Cho E, Seddon JM, Rosner B, Willett WC, Hankinson SE. Prospective study of intake of fruits, vegetables, vitamins, and carotenoids and risk of age-related maculopathy. Arch Opbthalmol. 2004;122: 883-892.

14. Gale CR, Hall NF, Phillips DI, Martyn CN. Lutein and zeaxanthin status and risk of age-related macular degeneration. Invest $O p b$ thalmol Vis Sci. 2003;44:2461-2465.

15. Seddon JM, Ajani UA, Sperduto RD, et al. Dietary carotenoids, vitamins $\mathrm{A}, \mathrm{C}$, and $\mathrm{E}$, and advanced age-related macular degeneration. Eye Disease Case-Control Study Group. JAMA. 1994;272: 1413-1420.

16. Snodderly DM. Evidence for protection against age-related macular degeneration by carotenoids and antioxidant vitamins. Am J Clin Nutr. 1995;62:1448S-1461S.

17. Beatty S, Boulton M, Henson D, Koh HH, Murray IJ. Macular pigment and age related macular degeneration. Br J Ophthalmol. 1999;83:867-877.

18. Beatty S, Murray IJ, Henson DB, Carden D, Koh H, Boulton ME. Macular pigment and risk for age-related macular degeneration in subjects from a Northern European population. Invest Ophthalmol Vis Sci. 2001;42:439-446.

19. Hammond BR Jr, Wooten BR, Snodderly DM. Individual variations in the spatial profile of human macular pigment. J opt Soc Am A Opt Image Sci Vis. 1997;14:1187-1196.

20. Hammond BR Jr, Wooten BR, Snodderly DM. Cigarette smoking and retinal carotenoids: implications for age-related macular degeneration. Vision Res. 1996;36:3003-3009.

21. Hammond BR Jr, Fuld K, Snodderly DM. Iris color and macular pigment optical density. Exp Eye Res. 1996;62:293-297.

22. Hammond BR Jr, Johnson EJ, Russell RM, et al. Dietary modification of human macular pigment density. Invest Ophthalmol Vis Sci. 1997;38:1795-1801.

23. Hammond BR Jr, Ciulla TA, Snodderly DM. Macular pigment density is reduced in obese subjects. Invest Ophthalmol Vis Sci. 2002; $43: 47-50$

24. Nolan J, O'Donovan O, Kavanagh $\mathrm{H}$, et al. Macular pigment and percentage of body fat. Invest Ophthalmol Vis Sci. 2004;45:3940 3950.

25. Curran-Celentano J, Hammond BR Jr, Ciulla TA, Cooper DA, Pratt LM, Danis RB. Relation between dietary intake, serum concentrations, and retinal concentrations of lutein and zeaxanthin in adults in a Midwest population. Am J Clin Nutr. 2001;74:796-802.

26. Sommerburg O, Keunen JE, Bird AC, van Kuijk FJ. Fruits and vegetables that are sources for lutein and zeaxanthin: the macular pigment in human eyes. Br J Opbthalmol. 1998;82:907-910.

27. Hammond CJ, Webster AR, Snieder H, Bird AC, Gilbert CE, Spector TD. Genetic influence on early age-related maculopathy: a twin study. Ophthalmology. 2002;109:730-736.

28. Klein RJ, Zeiss C, Chew EY, et al. Complement factor H polymorphism in age-related macular degeneration. Science. 2005;308: 385-389.

29. Seddon JM, Santangelo SL, Book K, Chong S, Cote J. A genomewide scan for age-related macular degeneration provides evidence for linkage to several chromosomal regions. Am J Hum Genet. 2003;73:780-790.

30. Seddon JM, Cote J, Page WF, Aggen SH, Neale MC. The US twin study of age-related macular degeneration: relative roles of genetic and environmental influences. Arch Ophthalmol. 2005;123:321327 .

31. Martin NG, Martin PG. The inheritance of scholastic abilities in a sample of twins. I. Ascertainments of the sample and diagnosis of zygosity. Ann Hum Genet. 1975;39:213-218.

32. Bone RA, Landrum JT, Fernandez L, Tarsis SL. Analysis of the macular pigment by HPLC: retinal distribution and age study. Invest Opbthalmol Vis Sci. 1988;29:843-849.

33. Mellerio J, Ahmadi-Lari S, van Kuijk F, Pauleikhoff D, Bird A, Marshall J. A portable instrument for measuring macular pigment with central fixation. Curr Eye Res. 2002;25:37-47.

34. Delori FC, Goger DG, Hammond BR, Snodderly DM, Burns SA. Macular pigment density measured by autofluorescence spectrometry: comparison with reflectometry and heterochromatic flicker photometry. J Opt Soc Am A Opt Image Sci Vis. 2001;18:1212-1230.

35. Delori FC, Dorey CK, Staurenghi G, Arend O, Goger DG, Weiter JJ. In vivo fluorescence of the ocular fundus exhibits retinal pig- 
ment epithelium lipofuscin characteristics. Invest Ophthalmol Vis Sci. 1995;36:718-729.

36. Delori FC. Autofluorescence method to measure macular pigment optical densities fluorometry and autofluorescence imaging. Arch Biochem Biophys. 2004;430:156-162.

37. Robson AG, Moreland JD, Pauleikhoff D, et al. Macular pigment density and distribution: comparison of fundus autofluorescence with minimum motion photometry. Vision Res. 2003;43:17651775.

38. Delori FC, Goger DG, Dorey CK. Age-related accumulation and spatial distribution of lipofuscin in RPE of normal subjects. Invest Ophthalmol Vis Sci. 2001;42:1855-1866.

39. Wustemeyer H, Moessner A, Jahn C, Wolf S. Macular pigment density in healthy subjects quantified with a modified confocal scanning laser ophthalmoscope. Graefes Arch Clin Exp Ophthalmol. 2003;241:647-651.

40. Neale MC. Mx: Statistical Modeling. Richmond, VA: Department of Psychiatry, Medical College of Virginia; 1997.

41. Neale MC, Cardon LA. Methodology for Genetic Studies of Twins and Families. Dordrecht, The Netherlands: Kluwer Academic Publishers; 1992.

42. Kyvic KO. Generalisability and assumptions of twin studies. In: Spector TD, Sneider H, MacGregor AJ, eds. Advances in Twin and Sib-Pair Analysis. London: Greenwich Medical Media; 2004:6777.

43. Beatty S, Koh HH, Carden D, Murray IJ. Macular pigment optical density measurement: a novel compact instrument. Ophthalmic Physiol Opt. 2000;20:105-111.

44. Werner JS, Donnelly SK, Kliegl R. Aging and human macular pigment density: appended with translations from the work of Max Schultze and Ewald Hering. Vision Res. 1987;27:257-268.

45. Ciulla TA, Curran-Celantano J, Cooper DA, et al. Macular pigment optical density in a midwestern sample. Ophthalmology. 2001; 108:730 - 737 .

46. Hammond BR Jr, Caruso-Avery M. Macular pigment optical density in a Southwestern sample. Invest Ophthalmol Vis Sci. 2000;41: 1492-1497.

47. Bone RA, Landrum JT, Gibert JC. Macular pigment and the edge hypothesis of flicker photometry. Vision Res. 2004;44:3045-3051.

48. Hammond BR Jr, Curran-Celentano J, Judd S, et al. Sex differences in macular pigment optical density: relation to plasma carotenoid concentrations and dietary patterns. Vision Res. 1996;36:20012012.

49. Bone RA, Sparrock JM. Comparison of macular pigment densities in human eyes. Vision Res. 1971;11:1057-1064.

50. Bone RA, Landrum JT, Dixon Z, Chen Y, Llerena CM. Lutein and zeaxanthin in the eyes, serum and diet of human subjects. Exp Eye Res. 2000;71:239-245.

51. Hammond BR Jr, Fuld K, Curran-Celentano J. Macular pigment density in monozygotic twins. Invest Ophthalmol Vis Sci. 1995; 36:2531-2541.

52. Beatty S, Nolan J, Kavanagh H, O'Donovan O. Macular pigment optical density and its relationship with serum and dietary levels of lutein and zeaxanthin. Arch Biochem Biophys. 2004;430:70-76.

53. Lowe GM, Bilton RF, Davies IG, Ford TC, Billington D, Young AJ. Carotenoid composition and antioxidant potential in subfractions of human low-density lipoprotein. Ann Clin Biochem. 1999; 36:323-332.

54. Middelberg RP, Spector TD, Swaminathan R, Snieder H. Genetic and environmental influences on lipids, lipoproteins, and apolipoproteins: effects of menopause. Arterioscler Thromb Vasc Biol. 2002;22:1142-1147.

55. Scholz M, Kraft HG, Lingenhel A, et al. Genetic control of lipoprotein(a) concentrations is different in Africans and Caucasians. Eur J Hum Genet. 1999;7:169-178.

56. Bhosale P, Larson AJ, Frederick JM, Southwick K, Thulin CD, Bernstein PS. Identification and characterization of a Pi isoform of glutathione S-transferase (GSTP1) as a zeaxanthin-binding protein in the macula of the human eye. J Biol Chem. 2004;279:4944749454.

57. Yemelyanov AY, Katz NB, Bernstein PS. Ligand-binding characterization of xanthophyll carotenoids to solubilized membrane proteins derived from human retina. Exp Eye Res. 2001;72:381-392.

58. Edwards AO, Ritter R III, Abel KJ, Manning A, Panhuysen C, Farrer LA. Complement factor $\mathrm{H}$ polymorphism and age-related macular degeneration. Science. 2005;308:421-424.

59. Berendschot TT, Broekmans WM, Klopping-Ketelaars IA, Kardinaal AF, Van Poppel G, van Norren D. Lens aging in relation to nutritional determinants and possible risk factors for age-related cataract. Arch Ophthalmol. 2002;120:1732-1737.

60. Andrew T, Hart DJ, Snieder H, de Lange M, Spector TD, MacGregor AJ. Are twins and singletons comparable? - a study of diseaserelated and lifestyle characteristics in adult women. Twin Res. 2001;4:464- 477 . 